\title{
ANALISIS PRODUKTIVITAS GAS HIDROGEN BERDASARKAN ARUS DAN TEGANGAN PADA PROSES ELEKTROLISIS $\mathrm{H}_{2} \mathrm{O}$
}

\author{
Fitriyanti \\ Jurusan Fisika, Fakultas Sains dan Teknologi, Universitas Islam Negeri Alauddin Makassar \\ email: fitriyanti_fisika@uin-alauddin.ac.id
}

\begin{abstract}
This study designed a $\mathrm{HHO}$ generator by separating oxygen (O2) and Hydrogen ( $\mathrm{H} 2)$ gas. The controlled variable is the $\mathrm{HHO}$ generator container made of plastic with a width of $12 \mathrm{~cm}$, length $24 \mathrm{~cm}$, height $20 \mathrm{~cm}$ in the shape of a rectangle, and filled with aquades as much as 1 litter, the distance between the electrodes is $1.5 \mathrm{~mm}$, the temperature that occurs during the electrolysis process is $33^{\circ} \mathrm{C}$ to $40^{\circ} \mathrm{C}$. The research variables observed were current and voltage used during the $\mathrm{H} 2 \mathrm{O}$ electrolysis process, Brown's gas flow rate in the measuring cup ( $\mathrm{ml} / \mathrm{min}$ ), the efficiency of the HHO generator, ie the energy or power used in the $\mathrm{H} 2 \mathrm{O}$ electrolysis process. Based on the research results obtained by the addition of a PWM Controller to increase the voltage can increase the productivity of the hydrogen gas produced. The value of the power needed affects the effectiveness of the electrolysis device, the greater the power needed, the effectiveness will decrease, this is influenced by the increasing amount of electricity consumption required in the operation of the tool.
\end{abstract}

Keywords: electrolysis, $\mathrm{HHO}$ generator, hydrogen.

\section{PENDAHULUAN}

Konsumsi energi di Indonesia meningkat rata-rata sebesar $7 \%$ per tahun seiring dengan meningkatnya jumlah penduduk, kegiatan ekonomi, dan perkembangan industri. Beberapa jenis energi di Indonesia diantaranya adalah minyak bumi, gas alam, batu bara, tenaga air, dan panas bumi..

Energi merupakan salah satu komponen penting bagi kelangsungan hidup manusia. Pada umumnya masyarakat masih banyak bergantung pada ketersedian sumber daya alam energi fosil yang sifatnya un-renewable, terutama minyak bumi yang semakin lama semakin terbatas jumlahnya Dalam perkembangannya, cadangan sumber energi di dunia semakin terbatas dan tidak mampu memenuhi kebutuhan manusia yang semakin bertambah. Berbagai penelitian telah dilakukan dalam rangka mengatasi ketersedian sumber daya alam yang terbatas jumlahnya tersebut, dalam hal ini disebut sebagai sumber energi alternatif.

Hidrogen dengan lambang kimia $\mathrm{H}$ merupakan unsur paling sederhana dilihat dari segi susunan proton dan elektronnya. Satu atom hidrogen hanya memiliki satu proton dan satu elektron. Gas hidrogen merupakan molekul diatomik, setiap molekulnya tersusun atas 2 atom hidrogen, yang secara kimia dirumuskan dengan H2. Berbagai penelitian telah membuktikan bahwa hidrogen mampu dijadikan sebagai sumber energi alternatif.

Kelebihan hidrogen dibandingkan dengan bahan bakar fosil lainnya yaitu pembakarannya tidak menyebabkan polusi karbon. Ketika terbakar, hidrogen 
melepaskan energi berupa panas dan menghasilkan air sebagai bahan buangan $\left(2 \mathrm{H}_{2}+\mathrm{O}_{2} \rightarrow 2 \mathrm{H}_{2} \mathrm{O}\right)$. lebih efektif dalam pembakaran dan jumlahnya di alam sangat melimpah sekitar $93 \%$ dari seluruh atom yang ada di alam.

Hidrogen $\left(\mathrm{H}_{2}\right)$ ini sebagai bahan bakar adalah sifatnya sebagai sumber energi yang tidak bersifat langsung (primer) sebagaimana halnya gas alam, minyak atau batubara. Hidrogen adalah energi turunan (Sekunder), yang diproduksi dengan menggunakan sumber energi lain seperti gas alam, minyak, batu bara, nuklir, energi matahari dan berbagai sumber energi lainnya. Karena bersifat sekunder itulah, untuk tahap awal penggunaan hidrogen sebagai bahan bakar, kita harus mengkombinasikan penggunaannya dengan bahan bakar primer (hibrida). Jadi fungsi hidrogen lebih sebagai bahan bakar pendamping yang berfungsi membantu mesin mengurangi konsumsi bahan bakar utama.

Kebanyakan dari hidrogen yang diproduksi sampai hari ini (di Amerika maupun di negara lain) adalah hidrogen yang didapat dari gas alam $(\mathrm{CH} 4)$ melalui proses yang disebut "steam reforming". Tapi yang lebih potensial untuk dilakukan dimasa depan adalah memproduksi hidrogen dari air melalui proses elektrolisis atau langsung menggunakan reaksi fotokimia. (Wannur, 2018)

Ada beberapa metode cara memproduksi gas hidrogen, salah satunya yaitu dengan metode elektrolisis air. Metode ini mengubah air $(\mathrm{H} 2 \mathrm{O})$ menjadi gas $\mathrm{HHO}$ (oxyhidrogen) atau biasa disebut dengan gas brown. Penggunaan hidrogen dalam sel bahan bakar merupakan teknologi yang menjanjikan untuk pemenuhan listrik dan panas dalam berbagai keperluan. Kendaraan dengan teknologi sel bahan bakar hidrogen bahkan dinilai memiliki efisiensi tiga kali lebih tinggi dibandingkan dengan kendaraan bermesin yang menggunakan bahan bakar bensin.

Proses elektrolisis air berjalan sangat lambat sehingga perlu diupayakan cara-cara untuk meningkatkan efisiensi produk. Misalnya dengan penambahan zat terlarut, yang bersifat elektrolit, modifikasi elektroda, variasi daya listrik yang digunakan atau dengan cara-cara lain yang mampu meningkatkan efisiensi produk. (Isana, 2010)

Elektrolisis air sebagai sumber hidrogen telah lama dipelajari dan telah menghasilkan berbagai penelitian yang terkait, hanya secara spesifik untuk menganalisis produktivitas dari beberapa metode yang dihasilkan masih perlu dikembangkan lebih lanjut. Dengan menganalisis seberapa banyak produktivitas hidrogen yang dihasilkan dari beberapa metode diharapkan mampu menghasilkan suatu alat generator $\mathrm{H} 2 \mathrm{O}$ dengan efektifitas yang tinggi

Dari beberapa penelitian yang telah dilakukan sebelumnya, penelitian ini akan memvariasikan besarnya arus dan tegangan yang diperlukan yang diharapkan dapat menciptakan suatu alat generator $\mathrm{HHO}$ dengan efektifitas yang tinggi. Efektifitas yang dimaksud disini adalah seberapa besar daya yang digunakan untuk menghasilkan gas hidrogen, sehingga dapat meningkatkan laju produksi dan efisiensi dari generator $\mathrm{HHO}$ yang dibuat.

Penelitian ini akan merancang sebuah alat elektrolisis yang mampu menghasilkan gas hidrogen dari air $\left(\mathrm{H}_{2} \mathrm{O}\right)$ dengan cara yang sederhana dan praktis, dan menganalisa efektivitas dari alat tersebut sehingga kedepannya mampu menghasilkan suatu alat elektrolisis dengan tingkat efisiensi yang tinggi.

\section{METODE PENELITIAN}

Jenis penelitian ini adalah penelitian kuantitatif. Penelitian ini untuk mengetahui efektivitas dari produksi gas hidrogen yang dihasilkan dari variasi 
arus dan tegangan serta luas penampang katoda dan anoda yang digunakan. Adapun lokasi penelitian terdapat di Laboratorium Elektronika Jurusan Fisika Fakultas Sains dan Teknologi UIN Alauddin Makassar.

Variabel terkontrol adalah wadah generator $\mathrm{HHO}$ terbuat dari plastik dengan lebar $12 \mathrm{~cm}$, panjang $24 \mathrm{~cm}$, tinggi $20 \mathrm{~cm}$ berbentuk persegi empat,dan diisi dengan aquades sebanyak 1 liter, jarak antara elektroda $1,5 \mathrm{~mm}$, suhu yang terjadi selama proses elektrolisis sebesar $33^{\circ} \mathrm{C}$ sampai $40^{\circ} \mathrm{C}$. Variabel penelitian yang diamati adalah arus dan tegangan yang digunakan saat proses elektrolisis $\mathrm{H} 2 \mathrm{O}$, laju aliran Brown's gas pada gelas ukur (ml/menit), efisiensi generator $\mathrm{HHO}$, yaitu energi atau daya yang digunakan pada proses elektrolisis $\mathrm{H} 2 \mathrm{O}$. Perumusan untuk mencari seberapa besar efektivitas produktifitas dari gas $\mathrm{HHO}$ adalah sebagai berikut :

a. Daya

$$
\mathrm{P}=\mathrm{V} \times \mathrm{I}
$$

Dimana :

$\mathrm{P}=$ Daya generator $\mathrm{HHO}$ (Watt)

$\mathrm{V}=$ Beda potensial/tegangan (Volt)

$\mathrm{I}=$ Arus listrik (Ampere)

b. Laju produksinya (flow rate gas $\mathrm{HHO}$ ) adalah :

Dimana :

$$
\mathrm{m}=\mathrm{Q} \times \rho_{\mathrm{HHO}}
$$

$\mathrm{m}=$ Laju produksi gas $\mathrm{HHO}(\mathrm{kg} / \mathrm{s})$

$\mathrm{Q}=$ Debit Produksi gas $\mathrm{HHO}(\mathrm{It} / \mathrm{s})$

$\rho=$ Massa jenis gas $\mathrm{HHO}$ (gram)

Dengan :

$$
Q=\frac{V}{t}
$$

$\mathrm{V}=$ Volume gas terukur (It)

$\mathrm{t}=$ Waktu produksi gas (s)

$(\rho \mathrm{HHO}=0,287 \mathrm{gr} / \mathrm{L})(\rho \mathrm{Hidrogen}=0,8988 \mathrm{gr} / \mathrm{L})(\rho \mathrm{ksigen}=0,219 \mathrm{gr} / \mathrm{L})$

c. Efisiensi Generator HHO.

$$
\eta H H O=\frac{Q H H O \times \rho H H O \times L H V H H O}{P} \times 100 \%
$$

Dimana:

$\eta \mathrm{HHO}=$ Efisiensi generator $\mathrm{HHO}(\%)$

$\mathrm{QHHO}=$ Debit produksi gas $\mathrm{HHO}(\mathrm{lt} / \mathrm{s})$

$\rho \mathrm{HHO}=$ Massa Jenis gas $\mathrm{HHO}(\mathrm{g} / \mathrm{tt})$

LHV HHO (Lower Heating Value) = LHV gas HHO $(119930 \mathrm{~J} / \mathrm{g})$

$\mathrm{P}=$ Daya generator $\mathrm{HHO}$ (Watt) 


\section{Diagram Alir Penelitian}

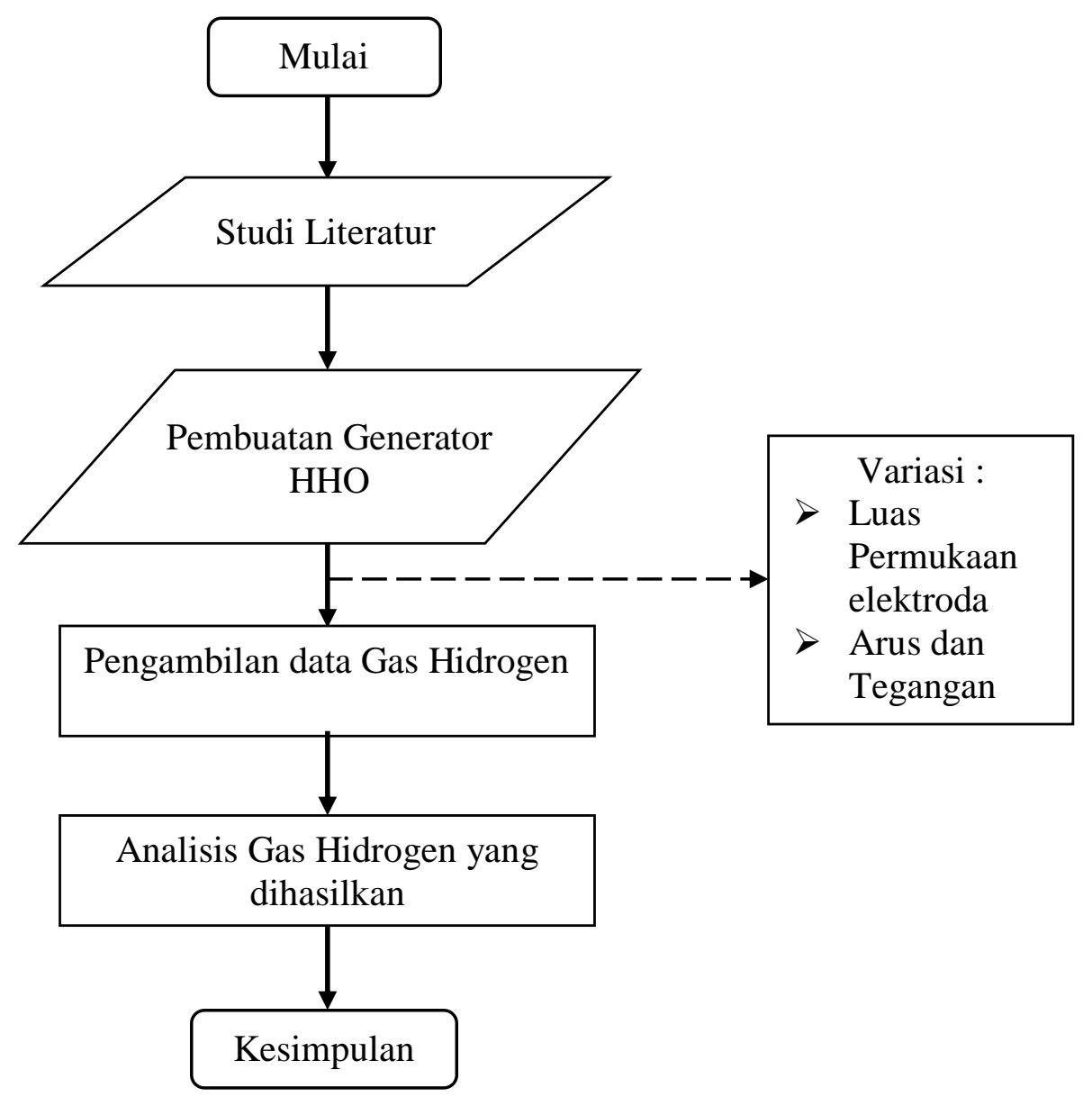

Gambar 1. Diagram alir penelitian

\section{HASIL DAN PEMBAHASAN}

\section{Hasil Penelitian}

Pengaruh Arus dan Tegangan pada Proses Elektrolisis $\mathrm{H}_{2} \mathrm{O}$

1. Tanpa PWM meter

Tegangan sumber DC (AKI), $v=12$ volt, Arus $(\mathrm{I})=3$ Ampere

Daya $(P)=v \times I=36$ Watt

suhu awal $=33^{\circ} \mathrm{C}$, suhu akhir $=44^{\circ} \mathrm{C}$ 


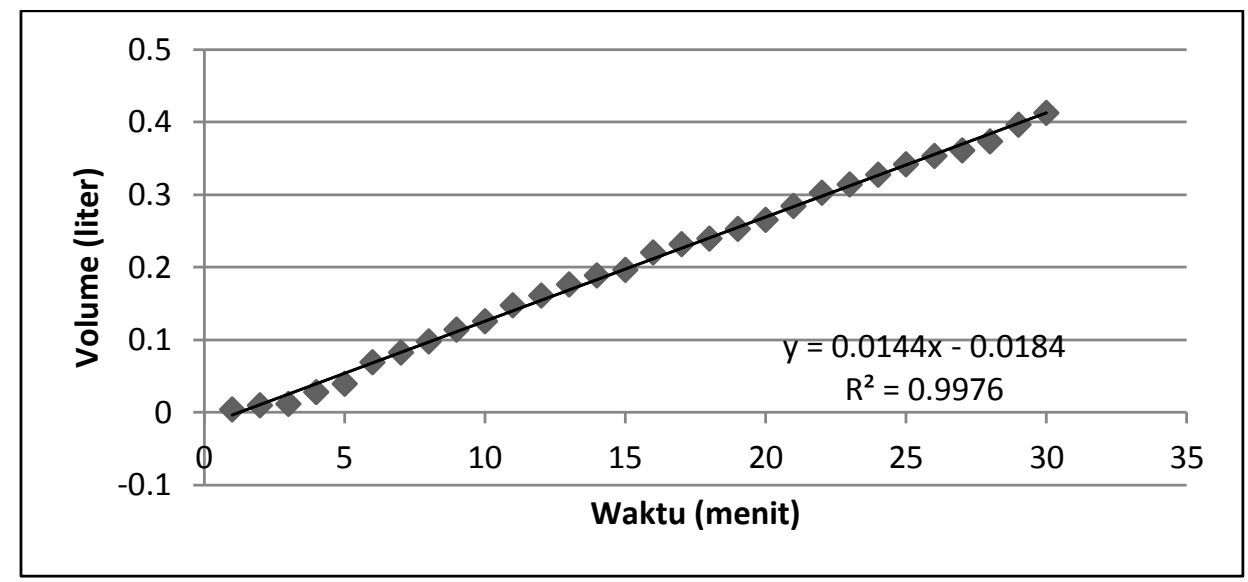

Gambar 2. Grafik hubungan volume gas (liter) dan waktu

Berdasarkan grafik pada gambar 2 dapat dilihat adanya kenaikan yang mendekati linear antara volume gas dalam proses elektrolisis $\mathrm{H}_{2} \mathrm{O}$ terhadap waktu yang diukur setiap 1 menit selama 30 menit. Hal ini dapat terjadi karena arus dan tegangan yang tercatat pada amperemeter dan voltmeter stabil jadi volume gas yang terbentuk juga mengalami kenaikan yang stabil dari menit yang satu kemenit yang berikutnya.

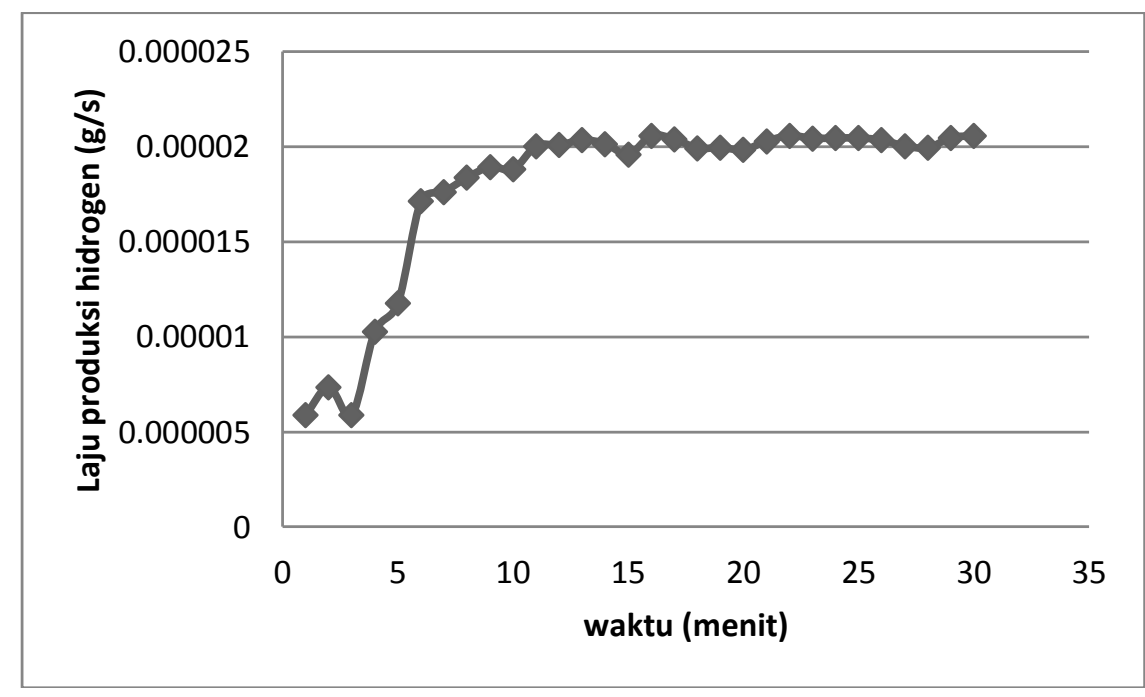

Gambar 3. Hubungan laju produksi gas hidrogen dengan waktu (menit)

Gambar 3 menunjukkan laju produksi gas hidrogen yang terbentuk, nilai laju produksi dihitung berdasarkan persamaan 2 pada grafik dapat dilihat laju produksi agak lambat pada menit pertama sekitar 7 menit pertama laju gas hidrogen mulai meningkat dan mendekati stabil pada menit kesepuluh. Hal ini disebabkan karena proses kerja alat membutuhkan waktu tanggap hingga mendapatkan nilai maksimal alat, adanya arus yang mengalir menyebabkan terjadinya pertukaran ion-ion antara elektroda dan $\mathrm{H}_{2} \mathrm{O}$ sehingga terjadi pemisahan antara gas oksigen dan hidrogen, efek yang timbul terjadinya 
kenaikan suhu pada proses elektrolisis sebesar $44^{\circ} \mathrm{C}$. Karena massa jenis gas lebih kecil dibandingkan aquades sehingga mengalir keluar. Proses ini berlangsung selama 30 menit.

\section{Dengan Menggunakan PWM Controller}

Tegangan sumber DC (AKI), $v=38$ volt, Arus $(\mathrm{I})=6.3$ Ampere

Daya $(P)=v \times I=239.4$ Watt

suhu awal $=33^{\circ} \mathrm{C}$, suhu akhir $=50^{\circ} \mathrm{C}$

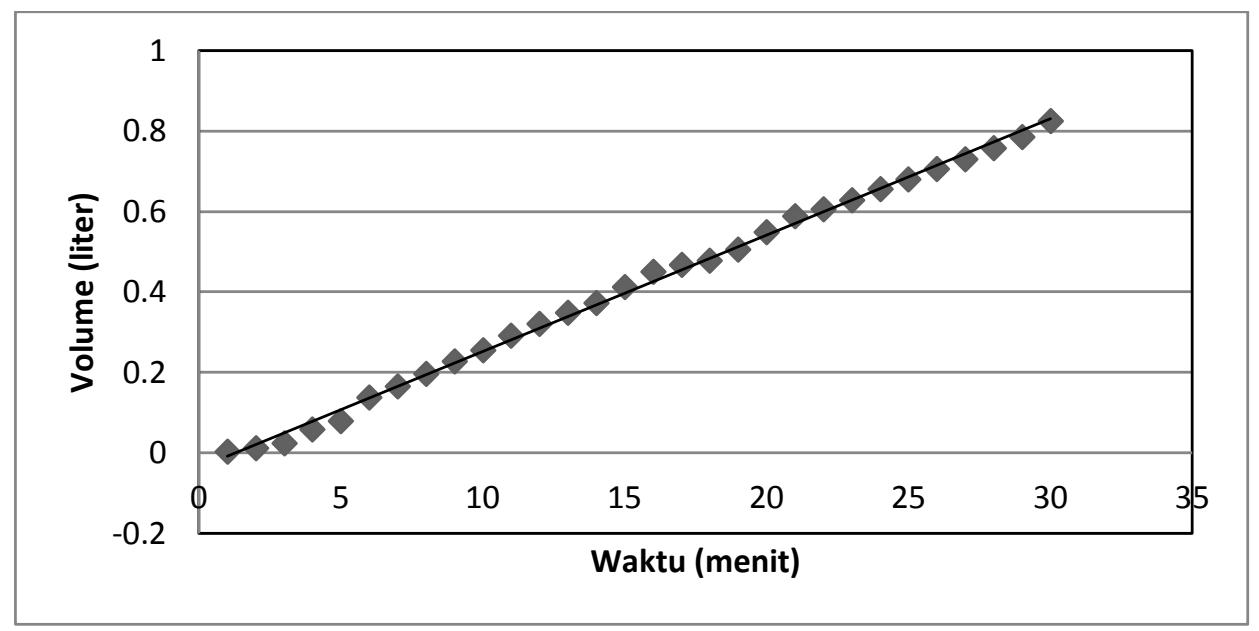

Gambar 4. Grafik hubungan volume gas (liter) dan waktu

Gambar 4 manunjukkan hubungan volume gas yang dihasilkan pada proses elektrolisis setiap menit selama 30 menit. Dengan menggunakan PWM Controller arus dan tegangan pada aki 12 volt, 60 Ah dapat ditingkatkan menjadi 38 volt dan 6.3 ampere. Proses pengambilan data dengan mengontrol agar arus dan tegangan yang terbaca pada voltmeter dan amperemeter statis dengan cara mengatur PWM Controller sedemikian rupa. Pada PWM Controller yang digunakan pada penelitian, maksimum pada tegangan 38 volt dan 6.3 ampere, di atas dari nilai tersebut nilai tegangan dan arus menjadi tidak stabil bahkan drop. Semakin besar nilai tegangan dan arus, maka volume gas hidrogen yang terbentuk juga semakin besar. Adanya peningkatan arus dan tegangan menyebabkan proses elektrolisis juga berlangsung cepat, karena perpindahan molekul-molekulnya juga semakin meningkat, suhu pada proses ini juga mengalami peningkatan disebabkan pergerakan ion-ion selama proses elektrolisis semakin cepat. Dengan suhu yang terukur pada termometer sebesar $50^{\circ} \mathrm{C}$. 


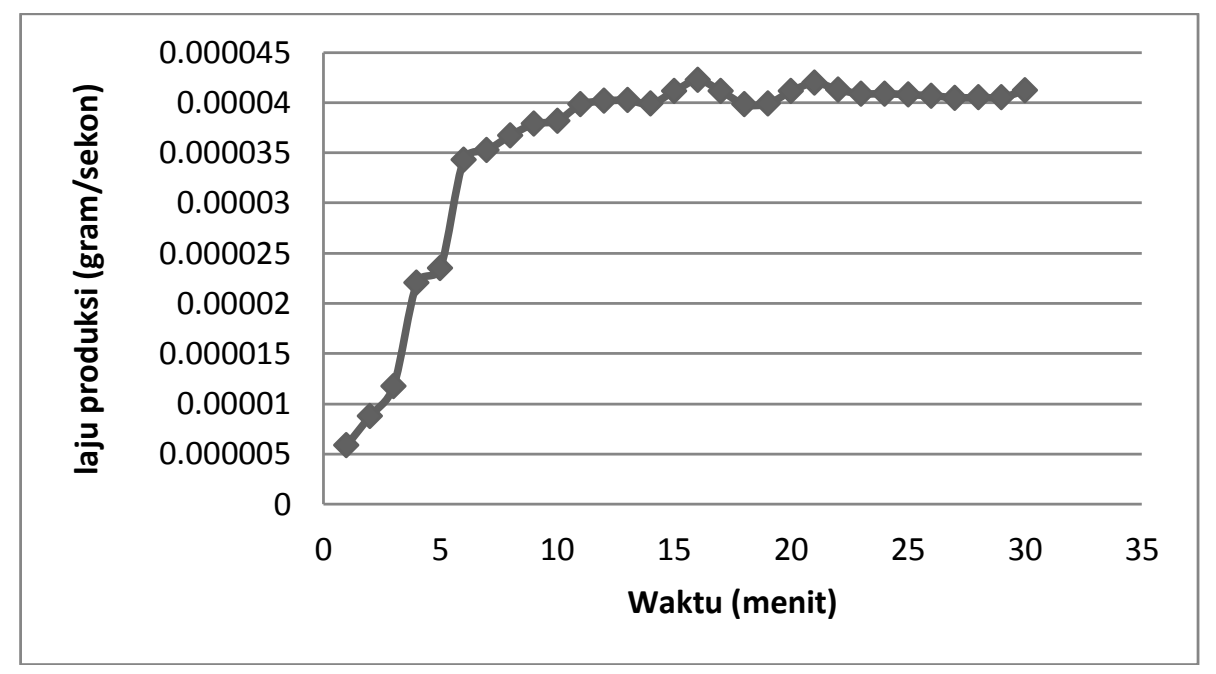

Gambar 5. Hubungan laju produksi gas hidrogen dengan waktu

Gambar 5 menunjukkan grafik laju produksi yang terbentuk pada proses elektrolisis setiap menit, sama halnya pada gambar 4 laju produksi pada menit pertama juga membutuhkan waktu untuk melakukan proses elektrolisis sehingga volume gas yang dihasilkan juga sedikit. Pada menit ke-7 laju produksinya mulai meningkat. Berdasarkan grafik terlihat adanya sedikit ketidakstabilan pada nilai laju produksi. Hal ini disebabkan karena pengaruh PWM Controller untuk menaikkan arus dan tegangan sumber. Pengontrolan harus terus dilakukan untuk mendapatkan nilai yang stabil juga.

\section{Pembahasan}

Besarnya volume gas yang terbentuk pada penelitian ini bergantung pada besarnya arus dan tegangan yang dapat memberikan hasil yang signifikan. Ratarata laju produksi gas hidrogen yang terbentuk pada arus dan tegangan 3 ampere dan 12 volt yaitu $1.78 \times 10^{-5}$ gram/liter dengan rata-rata debit volume gas sebesar 0.000199034 liter/sekon. Dengan mengubah besarnya arus dan tegangan yaitu 38 volt dan 6.3 ampere maka gas hidrogen yang dihasilkan juga meningkat. laju produksi rata-rata gas hidrogen yang dihasilkan sebesar $3.46 \mathrm{x}$ $10^{-5}$ gram/sekon dengan debit volume gas rata-rata sebesar 0.000396663 liter/sekon. Hasil maksimal diperoleh dengan meningkatkan arus dan tegangan, produksi gas hidrogen rata-rata sebesar $4.197 \times 10^{-5}$ gram/liter dengan rata-rata debit volume gas hidrogen perdetik yaitu 0.000467 liter/sekon.

Nilai efisiensi dicari dengan menggunakan persamaan 4 dapat dilihat pada tabel dibawah ini

Tabel 1. Nilai efisiensi generator $\mathrm{HHO}(\%)$

\begin{tabular}{|c|c|c|c|c|}
\hline No & $\begin{array}{c}\text { Tegangan } \\
\text { (Volt) }\end{array}$ & $\begin{array}{c}\text { Arus } \\
\text { (Ampere) }\end{array}$ & $\begin{array}{c}\text { Daya } \\
\text { (Watt) }\end{array}$ & $\begin{array}{c}\text { Efisiensi } \\
(\%)\end{array}$ \\
\hline 1 & 12 & 3 & 36 & 5,959 \\
\hline 3 & 38 & 6.3 & 239,4 & 1,786 \\
\hline
\end{tabular}

Berdasarkan tabel dapat disimpulkan bahwa efisiensi dipengaruhi oleh beberapa faktor yaitu produktivitas yang dinyatakan dengan volume alir, massa jenis gas $\mathrm{HHO}$, LHV HHO, dan energi yang digunakan untuk melakukan proses 
elektrolisis yang dinyatakan dengan daya. Besarnya daya, mempengaruhi peningkatan efisiensi pada generator $\mathrm{HHO}$. Apabila daya yang diperlukan tinggi maka efisiensi akan semakin menurun. Semakin besar arus dan tegangan yang digunakan maka konsumsi daya yang digunakan juga semakin besar. Penurunan efisiensi disebabkan oleh kenaikan energi listrik yang digunakan (Wiryawan, dkk 2013)

\section{SIMPULAN}

Telah dibuat sebuah alat elektrolisis sebagai Generator HHO, dengan variasi arus dan tegangan. Arus dan tegangan pada alat elektrolisis $\mathrm{H}_{2} \mathrm{O}$ mempengaruhi efektivitas dari generator $\mathrm{HHO}$, semakin besar arus dan tegangan menyebabkan semakin meningkatnya daya yang digunakan sehingga menyebabkan efektifitasnya menurun. Efisiensi yang terbaik didapatkan pada arus 3 Ampere dan tegangan 12 volt yaitu sebesar 5,959\%

\section{UCAPAN TERIMA KASIH}

Ucapan terimakasih penulis haturkan pada segenap tim dosen, staff Fisika UIN Alauddin Makassar beserta tim jurnal JFT atas selesainya penelitian ini. Beserta segenap pihak yang telah membantu penulis dalam proses penyelesaian penelitian

\section{DAFTAR PUSTAKA}

Achmad, H. 1992. Elektro Kimia dan Kinetika Kimia. Bandung : Citra Aditya Bakti. Emoto, M. 2006. The True Power Of Water. Bandung : MQ Publishing.

Brady, J.E. 1999. General Chemistry Principles And Structure. Jakarta: Binarupa Aksara.

Cheng, T.S. 1992. Chemistry Book 3. Second Edition. Singapura : EPB Publisher Pte.

Indarto Bachtera, 2015, Pengaruh Variasi Lapisan Pelat Sejajar pada Laju Produksi HHO dari Generator Oxyhydrogen Berbasis Sel Elektrolisisis, https://www.researchgate.net/publication/301900762.

Isyana S.Y.L, 2010. Perilaku Elektrolisis Air dengan Elektroda Stainless Steel. Yogyakarta Indonesia : Universitas Negeri Yogyakarta.

Michael Kwan, 2006. Prototype car runs 100 miles on four ounces of water as fuel. Mobile Magazine.

Sukardjo. 1989. Kimia Fisika. Jakarta : Rineka Cipta.

Wiryawan, D., D. Widhiyanuriyawan., N. Hamidi. 2013. Pengaruh Variasi Arus Listrik Terhadap Produksi Brown's Gas pada Elekrtroliser. Malang : Universitas Brawijaya. 